\title{
The Control Strategy of DFIG Combined with ESS in Islanded System
}

\author{
Yu Yong-yuan \\ Department of Electrical Engineering \\ Guizhou University \\ Guiyang, China \\ yyyboy@126.com \\ Hao Zheng-hang \\ Department of Electrical Engineering \\ Guizhou University \\ Guiyang, China \\ haozhenghang@163.com
}

\author{
Chen Zhuo \\ Department of Electrical Engineering \\ Guizhou University \\ Guiyang, China \\ 37495589@qq.com \\ Long Hang \\ Department of Electrical Engineering \\ Guizhou University \\ Guiyang, China \\ Windcrazier1942@sina.com
}

\begin{abstract}
For Double Fed Induction Generator (DFIG) in islanded system, a design is proposed which adds Energy Storage System (ESS) in the direct current side of the backto-back converter and changes the capacity of the load side converter. The generator-side converter of the system uses the power decoupling control strategy to achieve maximum power tracking. The load-side converter uses the constant voltage and frequency control strategy to achieve the constancy of voltage and frequency in islanded system. When switched to grid-connected mode, the phase synchronization control strategy based on frequency disturbance is applied to achieve the rapid phase synchronization of the grid and the islanded system. A simulation model is build and the results shows the effectiveness of the control strategy for the stable operation of islanded sys-tem and the rapid phase synchronization when the system is connected to the grid.
\end{abstract}

Keywords- DFIG; isolated system; mode switching; phase synchronization

\section{INTRODUCTION}

Because of the depletion of nonrenewable resources, more attention has been paid to new energy technologies. As one of the environment-friendly and inexhaustible renewable resources, the wind power technologies has been widely used around the world [1-2].

Double Fed Induction Generator (DFIG) is the mainstream of wind power generation. The study of DFIG generation system in islanded system is of much significance. This system can provide uninterruptable power during grid failure, improve the reliability of power supply. It also decrease long-range power transportation thus reduce the line loss. The introduction of wind power also optimizes the energy structure [3]. The stability control is the crucial mean to ensure the electricity quality of island sys-tem. Literature [4] proposes a variable pitch angle control of wind turbine combined with energy storage to limit wind power to overcome the disturbance of the wind speed to the micro grid operation. Literature [5] presents a forced stator-flux-oriented control strategy and build the control model, but the stator voltage control operate inefficiently and cannot achieve maximum wind power extraction. Literature [6] proposes the introduction of energy storage as the adjustment for power to suppress the fluctuation of both the wind power and the load.

This paper proposes a new design of back-to-back converter with an energy storage system for DFIG, a power control strategy for generator-side convertor and a constant voltage and frequency control strategy for loadside convertor. It also present a phase synchronization control strategy based on frequency disturbance. Simulation results shows that the design meet the stability requirement of islanded power supply system.

\section{MODELING AND CONTROL STRATEGY}

\section{A. System Structure}

The randomness of wind speed lead to the fluctuation of wind power and adverse effect to electricity quality. The disturbance of wind turbine or wind farm with reasonable capacity to the main grid when connected is limited due to the support of voltage and frequency from the main grid When islanded and without the support, the imbalance between the power wind turbine generates and the power load consumes as well as the fluctuation of wind speed will adversely affect the electricity quality. The introduction of energy storage system plays an important role for the improvement of electricity quality in the islanded wind power system [7-8].

The structure of DFIG combined with energy storage system is shown in Fig .1. The generator-side convertor controls the rotor flux, indirectly controls the active power, the reactive power and the voltage frequency of the stator of DFIG . The DC-side of the load-side convertor connects to the energy storage system, which consists of seriesparallel connected batteries with protection and equalization circuit [9]. The power density of the batteries are low and the cycle 


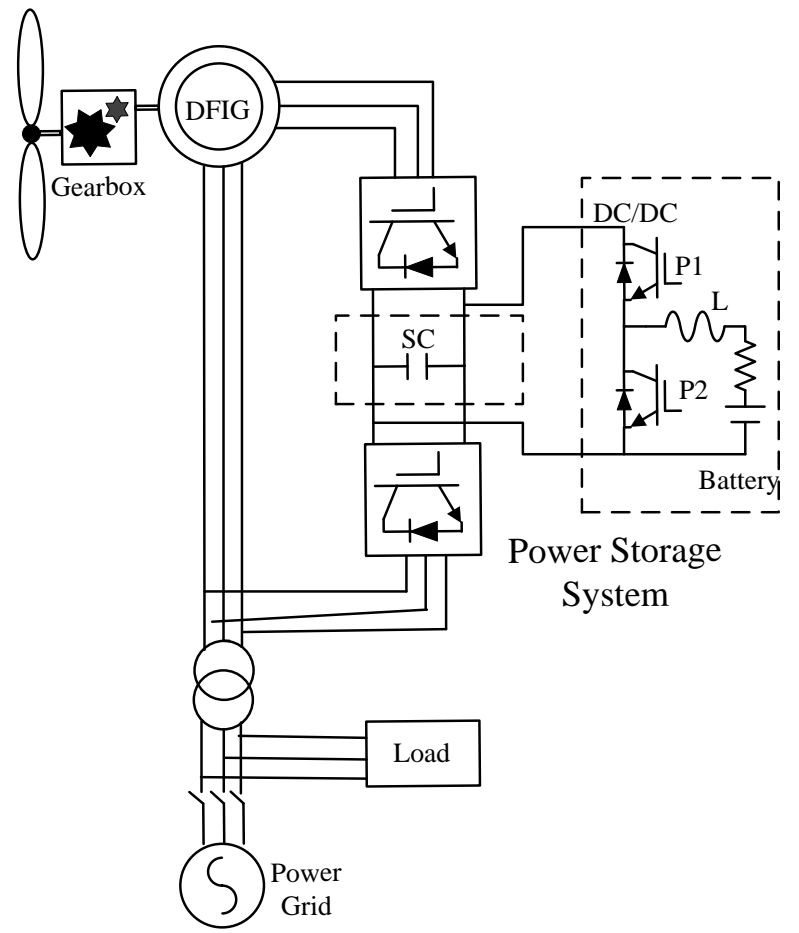

Figure 1. Structure of isolated system with wind generator

life are short, but the input cost is easily accepted. The super capacitors possess high power density and long cycle life but are expensive. A power storage module consists of these two equipment can rapidly and dynamically respond to the change of power and achieve long-time power management at the same time, with the performance of power storage improved, the life of batteries pro-longed, and the cost of the module save. In Fig .1, when DC/DC convertor P1 conducts, the batteries are charged by the DC bus. When P1 breaks, they are charged by the inductance. When P2 conducts, the batteries release energy to the inductance and when P2 breaks, the batteries and the inductance re-lease energy to the DC bus at the same time. On the one hand this module excites the rotor and deals with the change of the rotor slip power, on the other hand it connects the large-capacity load-side convertor to provide voltage and frequency support and equilibrate the unbalanced power of the isolated sys-tem. This paper proposes the phase synchronization control strategy based on frequency disturbance to achieve rapid synchronization when the isolated sys-tem parallels in the grid.

\section{B. The Model of DFIG}

The direction of current and voltage of the stator winding follows the generator convention, and those of the rotor winding follows the motor convention. In the synchronous rotating reference frame, the voltage and flux equations of DFIG for vector control are given blow.

The stator voltage is

$$
\left\{\begin{array}{l}
u_{\mathrm{d} s}=-r_{s} i_{\mathrm{d} s}-\omega_{1} \psi_{\mathrm{qq} s}+\frac{d}{d t} \psi_{\mathrm{d} s} \\
u_{\mathrm{q} s}=-r_{s} i_{\mathrm{q} s}-\omega_{1} \psi_{\mathrm{ds} s}+\frac{d}{d t} \psi_{\mathrm{q} s}
\end{array}\right.
$$

While the rotor voltage is

$$
\left\{\begin{array}{l}
\mathrm{u}_{\mathrm{dr}}=\mathrm{r}_{\mathrm{r}} \mathrm{i}_{\mathrm{dr}}-\left(\omega_{1}-\omega_{\mathrm{r}}\right) \Psi_{\mathrm{qr}}+\frac{\mathrm{d}}{\mathrm{dt}} \Psi_{\mathrm{dr}} \\
\mathrm{u}_{\mathrm{qr}}=\mathrm{r}_{\mathrm{r}} \mathrm{i}_{\mathrm{qr}}+\left(\omega_{1}-\omega_{\mathrm{r}}\right) \psi_{\mathrm{dr}}+\frac{\mathrm{d}}{\mathrm{dt}} \Psi_{\mathrm{qr}}
\end{array}\right.
$$

The stator flux is

$$
\left\{\begin{array}{l}
\Psi_{\mathrm{ds}}=-\mathrm{L}_{\mathrm{s}} \mathrm{i}_{\mathrm{ds}}+\mathrm{L}_{\mathrm{m}} \mathrm{i}_{\mathrm{dr}} \\
\Psi_{\mathrm{qs}}=-\mathrm{L}_{\mathrm{g}} \mathrm{1}_{\mathrm{qs}}+\mathrm{L}_{\mathrm{m}} \mathrm{i}_{\mathrm{qr}}
\end{array}\right.
$$

While the rotor voltage is

$$
\left\{\begin{array}{l}
\Psi_{\mathrm{dr}}=-\mathrm{L}_{\mathrm{m}} \mathrm{i}_{\mathrm{ds}}+\mathrm{L}_{\mathrm{r}} \mathrm{i}_{\mathrm{dr}} \\
\Psi_{\mathrm{qr}}=-\mathrm{L}_{\mathrm{m}} \mathrm{i}_{\mathrm{qs}}+\mathrm{L}_{\mathrm{r}} \mathrm{i}_{\mathrm{qr}}
\end{array}\right.
$$

Where $u$ is the voltage, $r$ is the resistance, $i$ is the current, $\omega_{1}$ and $\omega_{\mathrm{r}}$ are the synchronous angular velocity and rotor angular velocity, respectively. $\omega_{g}$ is the flip angular velocity an meet $\omega_{g}=\omega_{1}-\omega_{\mathrm{r}}, \psi$ is the flux, $L$, is the inductance, and $L_{\mathrm{r}}$ mutual inductance of rotor and stator. Subscript s and $r$ represent stator-side quantities and rotorside quantities, respectively, while subscript $d$ and $q$ represent the components of the two axes of the synchronous rotating reference frame.

\section{The Control Strategy for Islanded System}

\section{1) The Control Strategy for the Generator-side} Convertor

The control strategy block diagram for the generatorside converter of DFIG in isolated system is shown in Fig .2. Stator flux orientation is applied for the DFIG in isolated system, and the stator resistance is ignored, i.e. axis $d$ is in-phase with $\Psi_{s}$. The stator voltage $u$ is on the axis q, $\psi_{\mathrm{ds}}=\psi_{s}, \psi_{\mathrm{q} s}=0, u_{\mathrm{ds}}=0, u_{\mathrm{qs} s}=U_{s}=\omega_{1} \psi_{s}$, and substituted in the stator power equation of DFIG, then we can see that the active power of the stator is directly proportional with ${ }^{i_{\mathrm{qs}}}$ and the reactive power of stator is with $i_{\text {ds }}$. When the stator voltage $U_{s}$ and synchronous angular velocity $\omega_{1}$ are determined, $\psi_{s}$ is ascertainable. According to the stator flux equation, when $\psi_{s}$ is determined, the currents of stator and rotor are related. Then we can derive the equation of current and voltage of the stator and those of the stator, and control the generatorside converter to achieve the decoupling control of the active and reactive power of DFIG [10-11]. The intelligent memory method with an on-line training process is described for maximum power point track (MPPT) [12]. The rotor voltage equation under decoupling control

$$
\left\{\begin{array}{l}
u_{\mathrm{dr}}=u_{\mathrm{dr}}^{s}+\Delta u_{\mathrm{dr}} \\
u_{\mathrm{qr}}=u_{\mathrm{qr}}^{s}+\Delta u_{\mathrm{qr}}
\end{array}\right.
$$

While the decoupling terms are

$$
\left\{\begin{array}{l}
\mathrm{u}_{\mathrm{dr}}^{s}=\mathrm{r}_{\mathrm{r}} \mathrm{i}_{\mathrm{dr}}+\mathrm{L}_{\mathrm{r}}\left(1-\frac{\mathrm{L}_{\mathrm{m}}^{\mathrm{m}}}{\mathrm{L}_{\mathrm{g}} \mathrm{L}_{\mathrm{r}}}\right) \frac{\mathrm{d}}{\mathrm{dt}} \mathrm{i}_{\mathrm{dr}} \\
\mathrm{u}_{\mathrm{qr}}^{s}=\mathrm{r}_{\mathrm{r}} \mathrm{i}_{\mathrm{qr}}+\mathrm{L}_{\mathrm{r}}\left(1-\frac{\mathrm{L}_{\mathrm{m}}^{2}}{\mathrm{~L}_{\mathrm{s}} \mathrm{L}_{\mathrm{r}}}\right) \frac{\mathrm{d}}{\mathrm{dt}} \mathrm{i}_{\mathrm{qr}}
\end{array}\right.
$$

And the compensate terms are

$$
\left\{\begin{array}{l}
\Delta \mathrm{u}_{\mathrm{dr}}=-\omega_{\mathrm{s}}\left[\left(\mathrm{l}_{\mathrm{r}}-\mathrm{l}_{\mathrm{m}}^{2} / 1_{\mathrm{s}}\right) \mathrm{i}_{\mathrm{qr}}+\Psi_{\mathrm{qs}} \mathrm{l}_{\mathrm{m}} / 1_{\mathrm{s}}\right] \\
\Delta \mathrm{u}_{\mathrm{qr}}=\omega_{\mathrm{s}}\left[\left(\mathrm{l}_{\mathrm{r}}-\mathrm{l}_{\mathrm{m}}^{2} / 1_{\mathrm{s}}\right) \mathrm{i}_{\mathrm{dr}}+\Psi_{\mathrm{ds}} 1_{\mathrm{m}} / 1_{\mathrm{s}}\right]
\end{array}\right.
$$

The power equation are

$$
\left\{\begin{array}{l}
\mathrm{P}_{1}=\mathrm{U}_{\mathrm{s}} \mathrm{i}_{\mathrm{qs}} \\
\mathrm{Q}_{1}=\mathrm{U}_{s} \mathrm{i}_{\mathrm{ds}}
\end{array}\right.
$$

2) The Control Strategy for the Load-side Convertor 


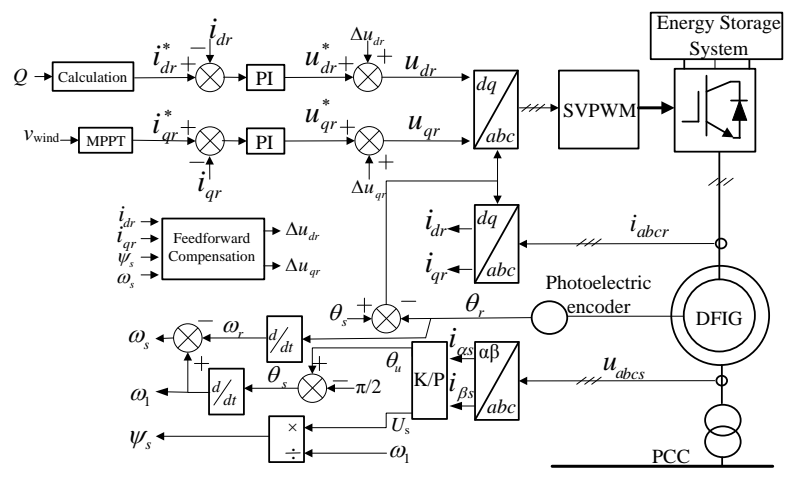

Figure 2. Control Strategy of the rotor-side converter

The capacity of traditional grid-side convertors is relatively small for the capacity of DFIG and can-not meet the requirement to balance the power of isolated system.

Large capacity convertor is adopted as load-side convertor in this paper. Cooperate with energy storage module, this convertor stabilize the voltage and frequency on the AC-bus of the isolated system. The control strategy of the load-side convertor is shown in Fig .3. The bus voltage of the system is fed to the controller of the convertor and com-pared with voltage reference, then output the modu-lated signal after a PI regulation, and generate the PWM pulses after the SVPWM unit, and drive the IGBT power module.

When the isolated system shift into grid-connected mode, the time for phase synchronization will be very long if the frequency difference of the two systems is small[1314]. The phase synchronization control strategy based on frequency disturbance is applied in this paper to achieve rapid phase synchronization. Before the connection, the phase angle of the grid voltage $\theta_{\mathrm{g}}$ is measured and compared with the phase angle of the bus voltage of the isolated system $\theta_{u}$. The difference is regard as the frequency disturbance after a PI regulation to disturb the bus frequency of the isolated system. As a result of the disturbance, $\theta_{u}$ changes relevantly until it is in-phase with the phase angle of the grid voltage. The strategy is capable to achieve rapid phase synchronization between the isolated system and the grid.

\section{III.SIMULATION AND ANALYSIS}

The simulation model is developed using Matlab/Simulink. The step is $1 \times 10-5 \mathrm{~s}$, simulate time is $10 \mathrm{~s}$, the rating power of DFIG is $2 \mathrm{MW}$, the rating wind speed is $12 \mathrm{~m} / \mathrm{s}$, the bus frequency of the system is $50.2 \mathrm{~Hz}$, the rating output voltage is $690 \mathrm{~V}$, and transformed to $10 \mathrm{kV}$ to connect to the load. Four situations are considered to verify this strategy.

\section{A. Situation 1 - Load Jump}

The load jumps from $1 \mathrm{MW}$ to $2 \mathrm{MW}$ at $\mathrm{t}=4 \mathrm{~s}$ while the wind speed is $9 \mathrm{~m} / \mathrm{s}$. Fig .4 shows the power which the system provides to the load and which DFIG generates. It can been observed from Fig .4 P\&Q_load that the active power from the system to the load jumps from 1MW to 2MW while the reac-tive power rarely change. It can be seen from Fig .4 P\&Q_Dfig that the jump of the load have

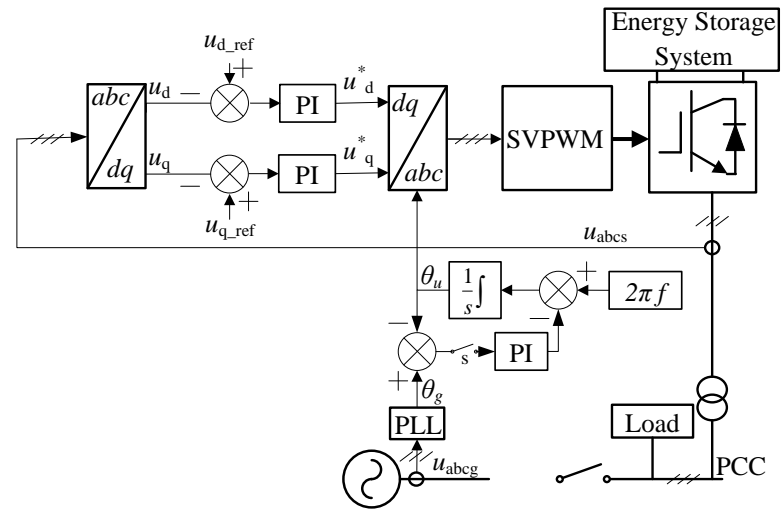

Figure 3. Control strategy of the load-side converter

no distinct effect on the power DFIG generates. The bus volt-age and current of the isolated system is shown in Fig .5. It can be seen that the bus voltage slightly fluctuates at $\mathrm{t}=4 \mathrm{~s}$ and rapidly recovers to the rating value, while the bus current increases to double as before. The rotor angular velocity of DFIG and the bus frequency of the system is shown in Fig .6. The simulation results of situation 1 shows that the jump of the load have no significant effect on the stability of the isolated system, the power supply of the sys-tem meet the requirement.

\section{B. Situation 2 - Wind Speed Jump}

The wind speed jumps from $9 \mathrm{~m} / \mathrm{s}$ to $12 \mathrm{~m} / \mathrm{s}$ at $\mathrm{t}=4 \mathrm{~s}$ while the load is $2 \mathrm{MW}$. Fig .7 shows the power which the system provides to the load and which DFIG generates. It can

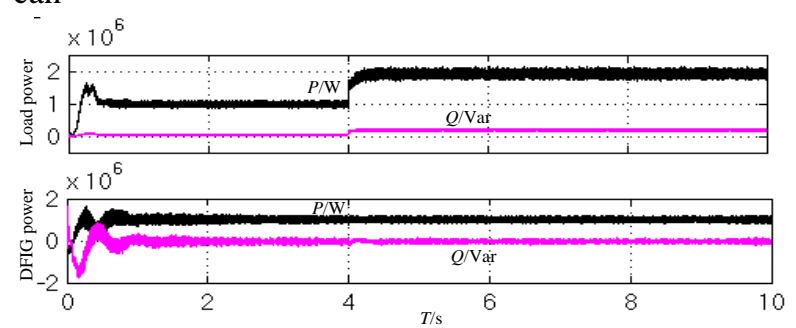

Figure 4. Real and reactive power of load and DFIG

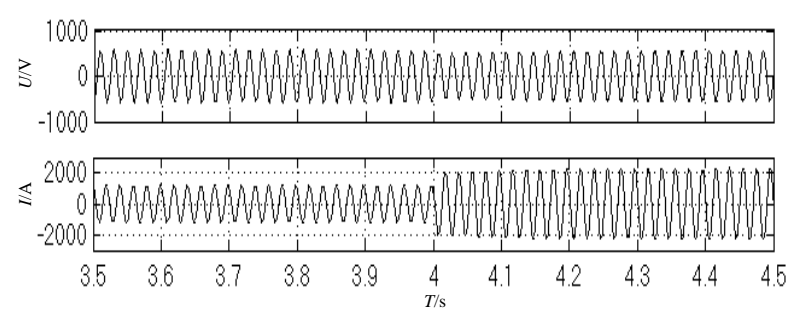

Figure 5. Bus voltage and current

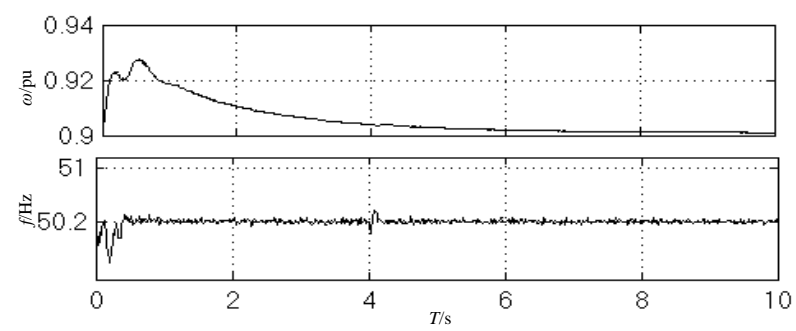

Figure 6. Rotor angular velocity of DFIG and Bus frequency 
been observed from Fig .7 P\&Q_Dfig that the active power DFIG generates jumps from $1 \mathrm{MW}$ to $2 \mathrm{MW}$. The bus voltage and cur-rent of the isolated system is shown in Fig .8, and it can be seen that they have no marked fluctuates when the wind speed jumps. The rotor angular velocity of DFIG and the bus frequency of the system is shown in Fig .9. The simulation results of this situation shows that the jump of the wind speed have no significant effect on the stability of the isolated sys-tem. The shortage of power is supported by the power storage module, and the power supply of the system meet the requirement.

\section{Situation 3 - Earthing Fault Disturbance}

An earthing fault occurs during $\mathrm{t}=3.8 \mathrm{~s}$ to $\mathrm{t}=4$.1 $\mathrm{s}$ while wind speed is $12 \mathrm{~m} / \mathrm{s}$ and the load is $2 \mathrm{MW}$. Fig .10 shows the power which the system provides to the load and which DFIG generates. The bus voltage and current of the isolated system is shown in Fig .11.

The rotor angular velocity of DFIG and the bus frequency of the system is shown in Fig .12. The system is unstable during the fault but recovers to origin state by self-adjustment after the fault. The simulation results of this situation shows that the isolated system is capable to recover after the fault is cleared, the system is of good steady and transient stability.

\section{Situation 4 - Initialize the grid-connection strategy}

The isolated system operates with the frequency of $50.2 \mathrm{~Hz}$ while the wind speed is $9 \mathrm{~m} / \mathrm{s}$ and the load is

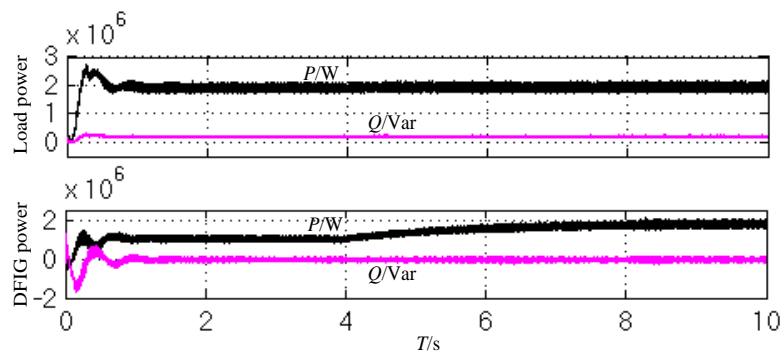

Figure 7. Real and reactive power of load and DFIG

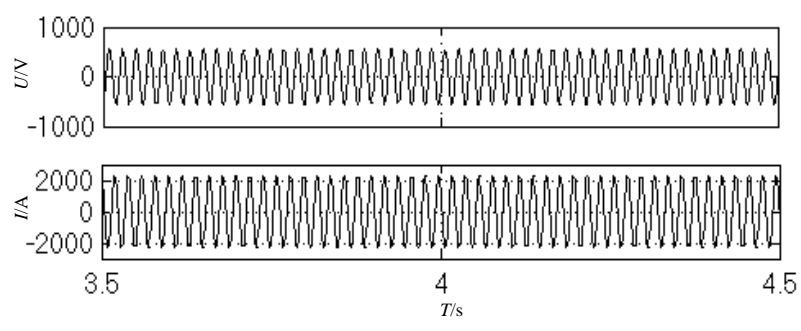

Figure 8. Bus voltage and current
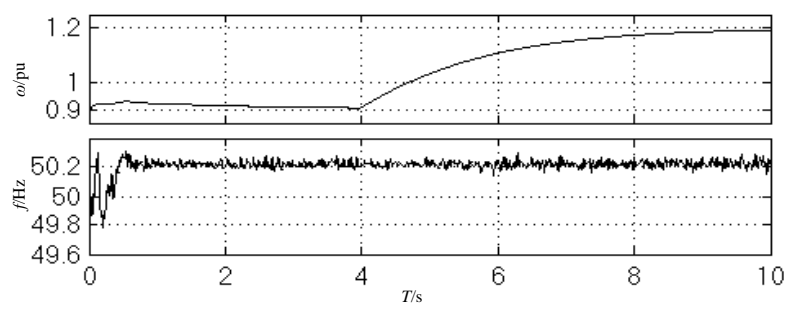

Figure 9. Rotor angular velocity of DFIG and Bus frequency
$1 \mathrm{MW}$, and the grid frequency is $49.8 \mathrm{~Hz}$. The phase synchronization control strategy based on frequency disturbance initializes at $\mathrm{t}=5.5 \mathrm{~s}$. The phase A voltage of the system and the grid after the initialization of the strategy is shown in Fig .13. The phase A voltage of the system and the grid without the initialization of the strategy is shown in Fig .14. The simulation results of this situation shows that this strategy is capable to achieve rapid phase synchronization be-tween the isolated system and the grid and accelerate the connecting process.

\section{CONCLUSION}

In this paper the system structure and control strategy of DFIG operating in isolated system is studied. According to the simulation results, the proposed strategy is capable to achieve the stable operation of the system under the jump of load and wind speed and the earthing fault. Also, the initialization of the phase synchronization control strategy based on frequency disturbance can accelerate

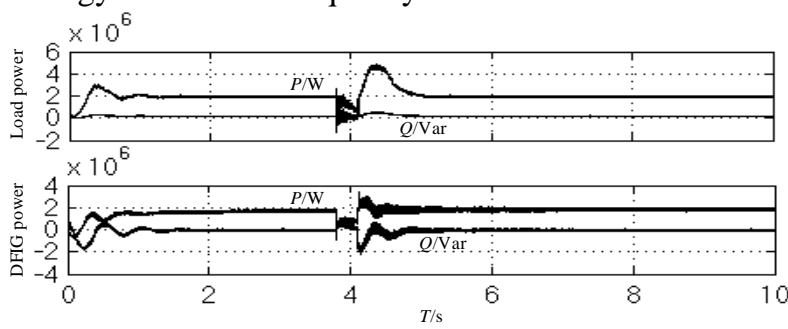

Figure 10. Real and reactive power of load and DFIG

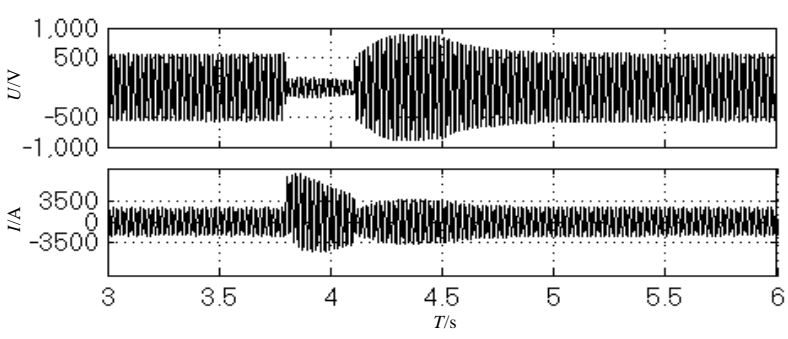

Figure 11. Bus voltage and current
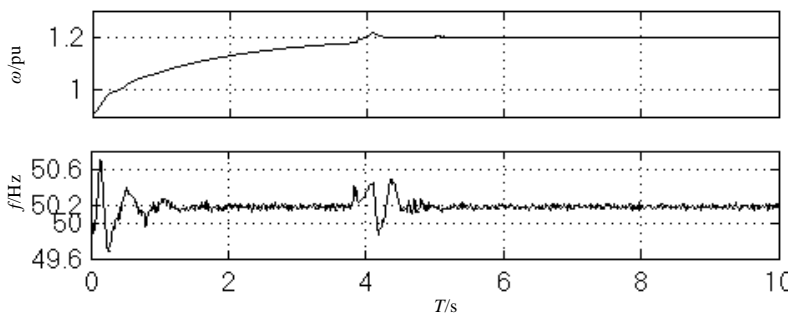

Figure 12. Rotor angular velocity of DFIG and Bus frequency

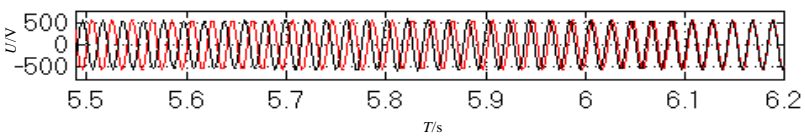

Figure 13. Phase A voltage with strategy

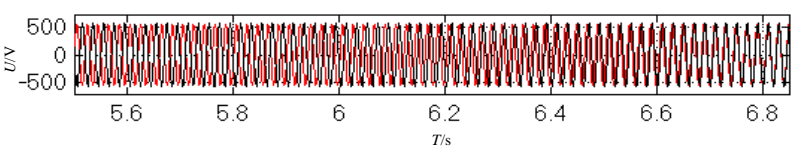

Figure 14. Phase A voltage without strategy 
process of phase synchronization between the isolated system and the grid, effectively improves the electric power quality of isolated power supply system.

\section{ACKNOWLEDGEMENT}

The authors gratefully acknowledge the support of the National Natural Science Fund of China (51467003)and the Introduce Talents Research Fund of Guizhou University, China(2014-07) and the Social Development Research Project of Guizhou Province, China (SY[2011]3081).

\section{REFERENCES}

[1] LUO Chen-xian. Wind Power Generation Today in the World and Prospect Forecast [J]. SINO-GLOBAL ENERGY, 2012, 17(3): 2431.J.

[2] Barton J, Infield D. Energy storage and its use with intermittent renewable enery $[\mathrm{J}]$. IEEE Transactions on Energy Conversiom, 2004, 19(2): 411-448.

[3] FENG Qing-dong. A Review of the State of the Art of Distributed Generation and Micro Grid [J], Electrical Measurement \& Instrumentation, 2013, 50(566): 54-59.

[4] LI Guo-qing, WANGHe, LI Hong-peng. Control strategy for DFIG-based wind farm in microgrid [J]. Electric Power Automation Equipment, 2013, 33(10): 1-7.

[5] ZOU Xu-dong, ZHAO Yang, LIU Bin. Research on Vector Control for Stand-Alone Doubly Fed Generator [J]. Proceedings of the CSEE, 2007, 27(12): 71-76.
[6] CAO Yun-feng,SHI Gang, PENG Si-min. Operation Control of an Islanded Power System Based on Wind-battery Hybrid Generation [J]. Power Electronics, 2011, 45(8): 75-77.

[7] HU Xi-tong, ZHAO Yan-lei, ZHANG Lei. Control Strategy for Energy Storage Converter of Wind Power Adjustment System [J]. Electrical Measurement \& Instrumentation, 2013, 50(573): 41-45.

[8] A Yazdani. Islanded Operation of a Doubly-fed Induction Generator wind-power System with Integrated Energy Storage [A] IEEE Canada Electrical Power Conference [C]. 2007: 1-7.

[9] T. Kim, W. Qiao, L. Qu. Power electronics-enabled self-X multicell batteries:A design toward smart batteries[J]. IEEE Transactions on Power Electronics, 2012, 27(11): 4723-4733

[10] DAI Hui, SHEN Jin-fei. Study on Stator-flux Oriented Vector Controled System ofDoubly Fed Induction Motor [J]. Power Electronics, 2010, 44(11): 62-64.

[11] HAO Zheng-hang, YU Yi-xin. The influence of doubly-fed induction generator on stability of power system [J]. Power System Protection and Control, 2011, 39(3): 7-11.

[12] Wang Q, Chang L. An Intelligent Maxmium Power Extraction Algorithm for Inverter-based Variable Speed Wind Turbine Systems [J]. IEEE Transactions on Energy Conversion, 2004, 19(5): 1242-1249.

[13] YANG Yang, SUN Kan, WANG Jian-hua. The Equipment of Distributed Power in Synchronized Grid-connected [J]. Science Technology and Engineering, 2011, 11(28): 6850-6854.

[14] GU Yong, WU Guo-xiang, TANG Hui. Flexible Grid-connection Control Strategy for VSCF Wind Power Generation [J]. Electrical Measurement \&Instrumentation, 2009, 46(521): 50-56. 